\section{CONSENT OF PATIENTS TO OPERATIONS.}

To the Editor of The Lancet.

Sir:-I am induced to address a few lines to you in order to receive your opinion, or that of some of your respected correspondents, on a subject which does not appear to me to be sufficiently well defined in surgical practice: $I$ refer to the age at which we should conceive the sanction or permission of the patient before proceeding to a severe operation (such as amputation of arm or leg), absolutely necessary.

A case lately camejunder my notice in which amputation of the leg was indispensable to save life. The patient was bet ween 14 and 15 years of age, with intellect fairly developed; and though his friends urged him to submit to the operation, he positively refused. I should mention that his limb was dreadfully shattered, having been run over by coal waggons; and that it was the unanimous opinion of four surgeons who saw him, that immediate amputation could alone save life.

These were the circumstances under which the question arose, whether we should (having received the permission of the friends), proceed by stratagem to perform the operation, or, with the certain loss of life, allow the limb to remain? We did not perform the operation until the following day, when a partial consent was given by the patient.

In the hope that this communication may draw forth some remarks in answer, $I \mathrm{am}$, Sir, your obedient servant,

H. G. Potter, M.R.C.S.L., \&c.

Newcastle-upon-Tyne,

Feb. 27, 1840 .

\section{DR. CARSON'S MODE OF SLAUGHTERING.}

\section{To the Editor of The LANCET.}

Sir:-Having read, in The Lancet of Saturday last, the article on "Dr. Carson's Patent Mode of Slaughtering Cattle," I am induced to offer a few observations on the subject. It appears that considerable opposition has beeu evinced on this subject, and that chiefly on the apparent cruelty attend. ing the "operation" to be performed on the animal. I remember reading in the "Times," some months ago, a long article on the subject, in which the shafts of ridicule were employed most unsparingly; at the same time an appeal was made to the feelings of the more sensitive of its readers on "this scientific mode of torturing animals," as it was termed. Now, it it has occurred to me that the object might be attained so as to arojd these objections, and in a more simple way. When an ox is slaughtered, the usual plan is to knock him on the head, when he falls, without afterwards moving a limb. Is not life effectually destroyed by this act? But the buteher, in order to drain the blood from the animal, afterwards cuts its throat. Now, this is what Dr. Carson wishes to retain; and would not the object be attained by simply omitting the latter operation? I am a non-medical man, and may be wrong, but, at all events, can do no harm in offering this suggestion to obviate an objection, which, it appears to me, will certainly have much weight with the prejudiced. Or, if it be necessary to employ Dr. Carson's method, would it not be done with the same advantage after the animal had fallen from the blow of the axe? Your obedient servant,

Sidney-street, City-road,

W. B. Steele.

Feb. 25, 1840.

\section{GOUT AND RHEUMATISM.}

\section{To the Editor of The Lancet.}

SIR:-I beg to state, through the medium of your pages, that $I$ have discovered a remedy for fixed, inflammatory gout, and acute rheumatism, which affords almost immediate relief in the most painful paroxysms of those merciless maladies, and speedily puts an end to them without the risk of metastasis.

I shall be happy to communicate the recipe and modus applicandi to any respectable practitioner who may desire them. I might state them here, were it not for the purpose to which they would be applied by unprin. cipled pretenders to the practice of physic. I am, Sir, your obedient servant,

King's Road, Chelsea,

$$
\text { S. W. Wanserough. }
$$

March 2, 1840.

** Mr. Wansbrough may depend on it that the benefits which the public disclosure of his plan might produce, would far outweigh the supposed disadvantages. What is to prevent the first applicant for the recipe from making it known in our pages?

\section{MEDICAL CIRCULARS-QUACKS AND PUFFS.}

\section{To the Editor of THE LANCET.}

Sin:-A family of whom $I$ have been for some time the medical attendant, having lately removed into the neighbourhood of the Hampstead Road, the inclosed circulax was forwarded to them soon after their taking possession of their new abode. It was left in the same manner as the trades- 